\title{
Leadership Presence at Work: A Practice - Oriented Framework
}

\author{
Charles D. Kerns \\ Pepperdine University \\ Corperformance, Inc.
}

Leadership or executive presence can be a nebulous concept, making it difficult for leaders to understand and put into practice. When behaviorally defined and operationalized, presence can strengthen a leader's personal brand equity, career competitiveness and organizational impact. After a brief review of some relevant literature, a four-phase practice-oriented framework is offered. This dynamic process helps a leader more fully understand and use leadership presence at work, including managing the relevant components. A leader profile which focuses on a set of eight behavioral practices for managing leadership presence is also provided, and some specific challenges associated with the process are considered.

Keywords: Behavioral Practices, Competitive Advantage, Impression Management, Leader Effectiveness, Leadership Presence Profile, Personal Brand Equity, Self-image Statement

\section{INTRODUCTION}

Quite often connected to the fields of organizational behavior and management, leadership or executive presence can be viewed through a personal branding and competitiveness lens. ${ }^{1}$ To the extent that leaders can effectively bring positive attention to themselves with enhanced leadership presence, they may enhance their influence, competitiveness and personal brand at work while also helping their organizations achieve desired results. This process of enhancing one's presence in the workplace implicates such topics as impression management, branding, differentiation, gaining competitive advantage, and leadership effectiveness.

The topic of self-presentation/impression management as studied in the field of applied behavioral science is particularly relevant to leadership presence (Bolino, Kacmar, Turnley \& Gilstrap, 2008; Kowalski, \& Leary, 1990; Leary \& Bolino, 2018). How a leader executes the behavioral practices associated with leadership presence has a dynamic impact on how others perceive the leader. The perceptions of others provide valuable information concerning a leader's effectiveness, reputation and/or presence (Love, Lim, \& Bednar, 2017). The study of self presentation/impression management, as Leary and Bolino (2018) indicate, presents a dynamic model of reciprocal influence. They observe that actors or leaders present themselves to others (make self-presentations), perceivers in turn form impressions of the actor or leader, and then actors or leaders react to the perceivers' responses. The desired outcome is to achieve congruity between a leader's intended self-presentation and the perceptions of others perceiving these behaviors. 
The concept of self presentation/impression management dates back to the work of Goffman (1959) with the publication of his book, The Presentation of Self in Everyday Life. Using self-presentation, individuals construct an image of themselves to project their identity and present themselves in a manner that is consistent with that image. These images are intended to be socially desirable (Ferris \& Sedikides, 2018). Self-presentation/impression management is not intended to be deceptive or manipulative. When people present themselves honestly and authentically, others tend to see them accurately (Murphy, 2007). Authenticity is a key aspect of projecting leadership presence (Ladkin \& Taylor, 2010; Leroy, Anseel, Gardner, \& Sels, 2015; van den Bosch, Taris, Schaufeli, Peeters \& Reijseger, 2019).

The concepts of branding, brand equity, and brand authenticity may be extrapolated from the field of marketing to help position and advance the understanding of leadership presence (Keller, 2012; Keller, 2010; Lair, 2005; Myers, 2017; Spear \& Roper, 2013; Ranfagni, Runfola \& Sarti, 2018): leaders who consistently project authentic presence likely strengthen the value of their personal brand. In addition, leadership presence implicates the study of performance management when presence is behaviorally defined and operationalized in ways that facilitate the measurement of desired outcomes (Schleicher, Baumann, Sullivan, Levy, Hargrove \& Barros-Rivera, 2018). Individual differences, as examined in the field of differential psychology, also relate to the study and practice of leadership presence (Zaccaro, Green, Dubrow \& Kolze, 2018) as leaders express themselves using different styles and work preferences. Consider also the work relating to work identity and leadership (Kyratsis, Atun, Phillips, Tracey, \& George, 2017; van Knippenberg, 2016) with the notion that a leader's presence and identity at work are being shaped over time and influenced by situational contexts (Kerns, 2018a; Lord \& Chui, 2018).

In recent years, the topic of executive presence has received substantial attention in the popular literature, recognizing that executive presence is an important aspect of leadership success (Crittenden, 2013; Macaux \& Bates, 2015). For example, recent research findings reveal that $89 \%$ of nearly 400 CEOs, communications executives and leaders in corporate professional development believe that leadership presence contributes to people getting ahead, while $78 \%$ believe that reduced leadership presence is an impediment to career advancement (Dagley \& Gaskin, 2014). In a separate study, research with senior executives further indicates that leadership presence positively impacts leaders' careers (Hewlett, Leader-Chivee, Sherbin, Gordon \& Dieudonne, 2012).

Conceptual and definitional clarity relative to leadership presence is distinctively lacking. Extant literature provides little in the way of evidenced-based practical frameworks, operational definitions and/or behavior focused practice profiles to advance understanding and application to work in this area. The current effort discussed in this article takes a more integrated approach to understanding and addressing the concept of leadership presence, providing a practice-oriented framework from which to view leadership presence. This framework and perspective offer an opportunity for leaders to systematically look at leadership presence as a process which draws upon various applied disciplines of study.

In this article, leadership presence is operationally defined as "displaying a set of key behavioral practices to achieve desired impacts." Leaders who identify, assess, understand and effectively project and manage leadership presence positively impact individuals, groups/teams, and the overall organization. Leadership presence can have a "ripple effect" by directly and indirectly influencing others (Marques, 2006). To advance the practice and study of leadership, the current definition focuses on the behavioral aspects of leadership presence which can be defined, assessed and managed to measure desired impacts. The current work pays particular attention to a set of key behavioral practices. While other less behaviorally based factors such as physical appearance and position status play roles in leadership presence, they are not a focus in the current operational definition and accompanying framework (Ford, Harding, Gilmore, \& Richardson, 2017).

Leadership presence is considered in its positive aspect in this article - used to enhance leadership effectiveness and lead the organization to reach its goals and results. However, the negative side of leadership presence should not be disregarded. With alarming rates of managerial ineffectiveness, and worse, it would be naïve to think that, in practice, leadership presence is only used to positive gain 
(Kaiser, LeBreton, \& Hogan, 2015). It is this author's belief that using thoughtful consideration to define what leadership presence is to any particular leader and to use leadership presence for the positive enhancement of organizational results, is key to successful managerial leadership. To this end, in this article, leadership presence is used in a positive way, with an eye toward growth, well-being and success.

\section{PRACTICE-ORIENTED FRAMEWORK}

A practice-oriented framework that addresses leadership presence is offered to help organizational leaders put presence into practice. The author has developed an integrated managerial leadership system that is associated with a leadership presence framework with four phases. ${ }^{2}$ This framework has been applied in a variety of settings, including work organizations, executive education and field studies.

The four phases illuminated in the framework are (I) defining and assessing; (II) affirming and understanding; (III) optimizing and integrating; (IV) measuring and evaluating (See Figure 1: Leadership Presence - Practice-Oriented Framework). The framework reflects a review of relevant literature, applied research, and practice by the author and his colleagues. These efforts have yielded the following observations that serve to support the framework offered in this article.

- Leaders displaying high levels of leadership/executive presence are frequently characterized as successful, confident and respected (Crittenden, 2013; Cuddy, Tannen \& Su, 2018).

- To be developed and managed, leadership presence needs to be clearly defined.

- Assessing leadership presence involves self-ratings and understanding the perceptions of others who are knowledgeable (Dagley \& Gaskin, 2014).

- "Just right" scaling methods yield useful information on the under or over use of specific behavioral leadership presence practices (Kaiser \& Overfield, 2010).

- Leadership experience across one's lifespan provides both positive and negative role models for executive presence (Kerns, 2018a).

- Exploring working identity is part of establishing presence at work and career advancement (Lord \& Chui, 2018).

- Self-presentation/impression management, self-image, and the self-enhancement motive contribute to the study and practice of leadership presence (Goffman, 1959; Leary \& Bolino, 2018; Pfeffer \& Fong, 2005).

- Developing a profile/performance-based job description helps a leader more fully understand the relationship between what she does and how she goes about doing it (Kerns, 2001). Leadership presence, however, extends beyond the functional role that a leader plays.

- Behavioral practices used to define leadership presence can be optimized through practice and/or coaching with the impact on leadership effectiveness and key organizational outcomes being enhanced over time (Dagley \& Gaskin, 2014; Vandaveer, Lowman, Pearlman \& Bannick, 2016).

- Competitive advantage, performance and well-being are connected to practices which enhance leadership presence (Clarke, Cornelissen \& Healey, 2019; Kerns, 2018b).

- Situational context matters when assessing and managing leadership presence (Johns, 2006).

- High impact communicating, decisive problem solving, and behavioral integrity are key practices for effectively enhancing leadership presence (Kerns, 2016a; Kerns, 2016b).

- The alignment of self-knowledge and external observable behavior helps to advance leadership presence (Carver, 2012; Ferris \& Sedikides, 2018).

- Attentiveness to the needs of others along with warm assertiveness contributes to a leader's presence (Buckingham \& Coffman, 1999; Wagner \& Harter, 2006).

- Research in neuroscience has application value for the practice of leadership presence (Chierchia \& Singer, 2016). 
- Handling pressure and displaying composure in stressful situations can enhance leadership presence (Baumeister, Schmeichel, \& Vohs, 2007; Duckworth \& Gross, 2014; Mitchell, Greenbaum, Vogel, Mawritz \& Keating, 2019).

- Drawing from the field of marketing, leadership presence can be viewed as a way to enhance one's personal brand as well as differentiate oneself (Andrusia \& Haskins, 2000; Keller, 2012; Keller, 2010; Myers, 2017; Spear \& Roper, 2013; Trump \& Brucks, 2010).

- While there is some evidence that leadership behaviors associated with leadership presence impact organizational innovation and growth (Seitchik, 2019), there is a paucity of empirical studies that directly investigate leadership presence.

- Both behavioral and non-behavioral based factors have been espoused in defining leadership/executive presence (Ford, Harding, Gilmore, \& Richardson, 2017; Hewlett, Leader-Chivee, Sherbin, Gordon \& Dieudonne, 2012; Voras, 2000).

- Executive presence is primarily presented as a positive force, with little attention being given to its potential dark side (Dagley \& Gaskin, 2014; Kaiser, Le Breton, \& Hogan, 2015).

- Individual differences and dispositional factors as well as the perceptions of others interact and play a role in a leader's presence (Voros, 2000; Zaccaro, Green, Dubrow \& Kolze, 2018).

The framework discussed in this article seeks to help leaders define-assess, affirm-understand, optimize-integrate, and measure-evaluate desired impacts of executive or leadership presence to integrate the practice of managing executive presence into their daily work. The Leadership Presence PracticeOriented Framework depicted below helps "operationalize" the definition of leadership presence and the related process. 


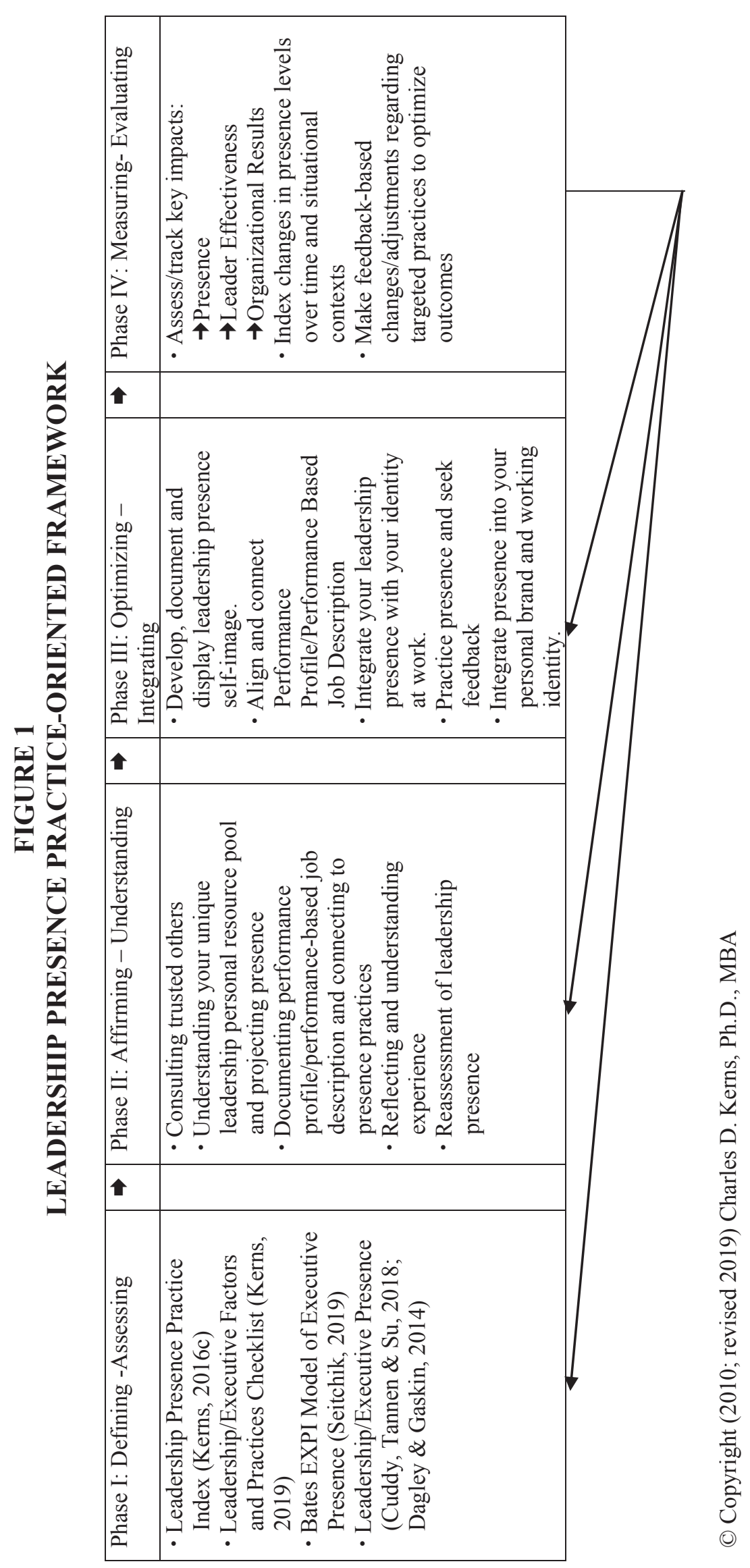




\section{Phases of the Leadership Presence Practice Framework}

The leadership presence practice framework contains four phases, reviewed below. Key content areas, actions and behavioral outcomes associated with each phase are briefly discussed. Implementation of the framework is typically facilitated by an executive coach or trusted advisor.

\section{Phase 1: Defining and Assessing}

The starting point in Phase I is recognizing the importance of defining leadership presence in terms of behavioral practices that can be observed and assessed. This is especially important given the sundry of definitions that are found in the literature surrounding the topic of leadership/executive presence. There are a number of ways to assist leaders in identifying and defining behavioral correlates of leadership presence. Successful leadership presence is influenced by situational context - it will be identified in the context of the leader's personal attributes, performance profile, and his role within the organization.

The Leadership Presence Practice Index as noted in Figure 1 was developed and has been used to help leaders focus on key evidenced based practices that influence a leader's presence (Kerns, 2016c). These practices are as follows:

- High-impact communicating

- Decisive problem-solving

- Showing interest and support in others

- Displaying composure

- Showing warm assertiveness

- Managing core values

- Delivering desired outcomes/results

- Displaying self-knowledge and awareness

Other assessment tools are available to help leaders specifically focus on factors and to expand and refine what executive presence means to them, such as the Bates EXPI Model of Executive Presence which measures perceptions of three dimensions which include character, substance, and style (Seitchik, 2019). The popular literature abounds with lists of concepts and terms that are offered as ways to understand executive presence.

Once a leader has identified the various behavioral practices and factors he believes are important for his leadership presence, the leader will assess where he stands on each dimension - how effective is he now for each practice/factor?

Beyond using targeted assessment tools to define and measure behavioral practices and factors making up leadership presence, additional instruments are being developed such as the Leadership/Executive Factors and Practices Checklist (Kerns, 2019). These types of checklists help guide leaders in identifying and prioritizing a set of practice areas that they believe profile leadership presence in the context of their own work and position. The Leadership/Executive Factors and Practice Checklist has been used to help organizations customize their approach to defining and assessing leadership/executive presence. The behavioral outcomes for Phase I are:

- Defining leadership presence.

- Specifying a set of relevant and applicable behavioral practices that index presence.

- Assessing leadership presence.

\section{Phase II: Affirming and Understanding}

Once leadership presence has been defined and assessed in Phase I, it is important that the associated behavioral practices be affirmed and understood. This involves seeking input from others to determine whether there is agreement in the perceptions of the behavioral practices that were identified as being important for leadership presence by the leader. These consultations should be with trusted others who know the leader well and are willing to give honest feedback. This exchange should assist the individual in better understanding how his ratings are impacting his leadership presence at work. The dialogue should include how the individual's leadership presence is influencing his execution of his performance- 
based job description or functional work role. Understanding and appreciating how the individual's uniqueness can be integrated into his leadership presence is considered and reviewed. Upon reflection and review of this process, if reassessment seems to be indicated, then the individual should re-assess his leadership presence practice ratings, then proceed as appropriate with a fuller understanding of his leadership presence. The behavioral outcomes for Phase II are:

- Receive useful feedback on leadership presence.

- Understand the relationship between leadership presence and executing the leader's functional work role.

- Reflect on assessment and feedback and consider if reassessment is warranted.

\section{Phase III: Optimizing and Integrating}

After leadership presence practices have been affirmed and more fully understood, many useful things can be done to help optimize and integrate the execution of the behavioral practices. For example, developing and documenting a leadership presence self-image statement of what leadership presence looks like for the individual is useful and valuable. This process helps to optimize and integrate the execution of the targeted behavioral practice areas. Optimizing behavioral practices is also supported by the development and integration of these practices with a Performance Profile/Performance Based Job Description (Kerns, 2001). This process helps the individual more clearly align and connect her functional work role with the practices associated with enhancing her leadership presence. Obtaining useful feedback on how effectively one is displaying her leadership presence is also important to optimizing and integrating the development of these behavioral practices. Executing these practices along with referencing one's positive and unique self-image of leadership presence helps one strengthen her personal brand and presence at work. The behavioral outcomes for Phase III are:

- Develop, document and act in alignment with one's leadership presence self-image.

- Align and connect presence with the execution of one's Performance Profile/Performance Based Job Description.

- Practice presence behavioral practices and seek feedback.

- Integrate unique displays of leadership presence into one's personal brand.

\section{Phase IV: Measuring and Evaluating}

Measuring and evaluating the impact that one's execution of practices associated with enhancing leadership presence is having on the attainment of desired outcomes is an important component in the framework. Measuring and evaluating presence is especially important in determining if leaders are influencing desired outcomes such as achieving agreed upon key results and impacting other desired organizational outcomes such as well-being, innovation, and revenues (Kerns, 2018b; Seitchik, 2019). Feedback gleaned from this measurement and evaluation process also becomes a basis for making behavioral changes and/or adjustments to optimize and integrate leadership presence practices. The behavioral outcomes for Phase IV are:

- Track and measure key impacts including presence, leader effectiveness and organizationalwide outcomes.

- Make feedback-based changes and adjustments regarding targeted practices to optimize outcomes.

\section{LEADERSHIP PRESENCE PROFILE}

A leader's efforts in implementing the four-phase framework are advanced when he effectively displays a set of key behavioral practices. Eight specific behavioral skill areas are suggested to create a leader profile that can help leaders assess and manage their leadership presence. This profile can also be employed by executive coaches and trusted advisors to help leaders in their implementation of the framework. The eight behavioral practice areas composing the profile are briefly reviewed below. 


\section{High - Impact Communicating}

Throughout the four phases, the need for high-impact communication is essential. High-impact communication is achieved when the leader's intent has the desired impact on others on a consistent basis (Kerns, 2016a). Leadership presence is enhanced when a leader is routinely understood by others. This interpersonal influence skill enhances leadership presence when a leader:

- speaks clearly using appropriate tone, words and pace,

- understands what is in his perceptual filter regarding the topic at hand,

- receiver-orients his message and recognizes what is in the receiver's perceptual filter regarding the topic being addressed,

- offers a coherent message wherein "what" is being said aligns with "how" it is being offered,

- actively listens to others, and

- remains open to feedback from others regarding whether or not his intended message has the desired impact.

As a leader works to optimize his leadership presence, it is important that he track how he is doing in practicing high-impact communicating as part of Phases III (optimizing and integrating) and IV (measuring and evaluating). A useful metric for tracking and measuring high-impact communicating is the ratio of intent to impact. The leader and/or his coach regularly measure the leader's perception (and those of selective others) regarding how often he believes his intended messages are having the desired impact. These observations are used as a springboard to strengthen the leader's presence as it relates to practicing high-impact communicating.

\section{Decisive Problem Solving}

Decisive problem solving occurs when desired outcomes are achieved in agreed upon timeframes using the right amount of quality information. Leadership presence is diminished when the leader takes too long to make a decision, or when decisions are based on non-essential information or are made too hastily, without essential information. The leader needs to weigh time considerations with the quality of information acquired at any point during the process. In the end, leadership presence is either enhanced or diminished by whether or not desired outcomes have been achieved, as considered during Phase IV (measuring and evaluating). It is important for the leader to recognize, as she strives to enhance leadership presence, that decisive problem solving does not necessarily mean making quick decisions. Enhancing one's leadership presence through decisive problem solving includes managing the delicate balance between the desire for quality information and time pressures to achieve desired outcomes on schedule (Kerns, 2016b).

The decisive-problem solving ratio is a practical metric to consider when evaluating a leader's leadership presence. This measurement process involves having a leader estimate the number of desired outcomes that she has achieved and/or significantly influenced in comparison to decisions which did not yield the agreed upon outcome. As with the high-impact communication measurement metric, a leader should rate herself and have selected others offer their perception of the leader's decisive-problem solving ratio. These observations become important sources of information as the leader works to further develop decisive problem-solving skills in connection to enhancing leadership presence.

\section{Showing Interest and Support}

Leadership presence includes actions which demonstrate a leader's engagement with her people. The Gallup organization has documented work which demonstrates the importance for leaders to show that they care about their people and their peoples' development (Buckingham \& Coffman, 1999; Wagner \& Harter, 2006). Based on extensive interviews of millions of employees with regard to successful leadership presence by the Gallup organization, employees who felt supported agreed with the following sentiments:

- My supervisor, or someone at work, seems to care about me as a person.

- There is someone at work who encourages my development. 
As suggested by these findings, successful leaders are present and engaged with their people. The author's and his colleague's work aligns with these two observations and further supports the proposition that successful leaders show interest and support in others. It seems that when a leader is engaged with his people his approachability increases (Kerns, 2014). Leaders who are more approachable become privy to what's going on around them and people are more apt to see them as a resource. The use of an approachability index is one useful way to measure this leadership presence practice. A leader's approachability index is found by asking the leader and selected others to what extent ( $0-10$ with 10 being the highest) is the leader approachable? In interviews conducted to obtain these ratings, it is often revealed that the leaders who rate high on approachability do things to show interest in others including supporting their development in ways that advance their careers.

\section{Displaying Composure}

Maintaining one's leadership presence is often challenged when a leader is under pressure or otherwise placed in a stressful situation (Harms, Credé, Tynan, Leon \& Jeung, 2017; Mawritz, Greenbaum, Butts \& Graham, 2017). It is in these circumstances when a leader's dark side may emerge, increasing the chances that her leadership presence behaviors may diminish (Baumeister, Schmeichel \& Vohs, 2007; Kaiser, Le Breton, \& Hogan, 2013). The author and his colleagues have found that leaders seem to have unique "hot buttons" that can, when pushed, cause the leaders to lose their composure (Kerns, 2013). Displaying composure in the face of stressful and perhaps distressing circumstances means responding professionally rather than personally. These leaders use effective self-control strategies. When asked by the author, leaders almost always respond that quick knee jerk reactions most often lead to negative/undesired outcomes. Leaders with high leadership presence control this tendency to react quickly, especially in relation to "hot button" situations.

The "Maturity Index" has proven to be a useful tool in helping leaders measure their tendencies when it comes to facing stressful and/or distressing situations. With the Maturity Index, a leader and selected others are asked to rate from 0-10 (10 being the highest level of maturity) to what extent the leader responds to stressful/upsetting situations with poise and professionalism as opposed to personally and immaturely.

\section{Showing Warm Assertiveness}

Leaders can be viewed along two behavioral dimensions that interact with leadership presence (Buzzotta, Lefton, \& Sherberg, 1982). One dimension concerns the extent to which they push to get what they want in interactions with others, i.e. level of assertiveness. One's level of assertiveness can range from being passive (rarely seeking to get what you want) to dominating (always seeking to get what you want). The other dimension relates to one's level of interpersonal warmth when interacting with others. One's level of warmth can range from being cold to warm. In terms of leadership presence, the preferred way to enhance one's presence is to interact with others using a warm assertive approach that makes it clear where the leader stands on a topic in a way that helps preserve and/or strengthen the relationship.

The ability to empathize (showing that you understand others' perspectives and feelings) is clearly connected to the display of warmth. Emerging neuroscience research indicates that over ninety percent of individuals have an inborn capacity to be empathetic (Chierchia \& Singer, 2016). However, Elsbach and Stigliani (2018) report that most individuals do not express empathy in their daily lives but that research is indicating that empathy can be developed. This line of work would seem to hold promise for leaders who are seeking to enhance their expression of warmth and empathy.

An effective way for a leader and others to assess the leader's level of assertiveness and warmth is to have them plot where they are on the graphic found in Figure 2. 
FIGURE 2

LEADERSHIP PRESENCE: ASSERTIVENESS - WARMTH

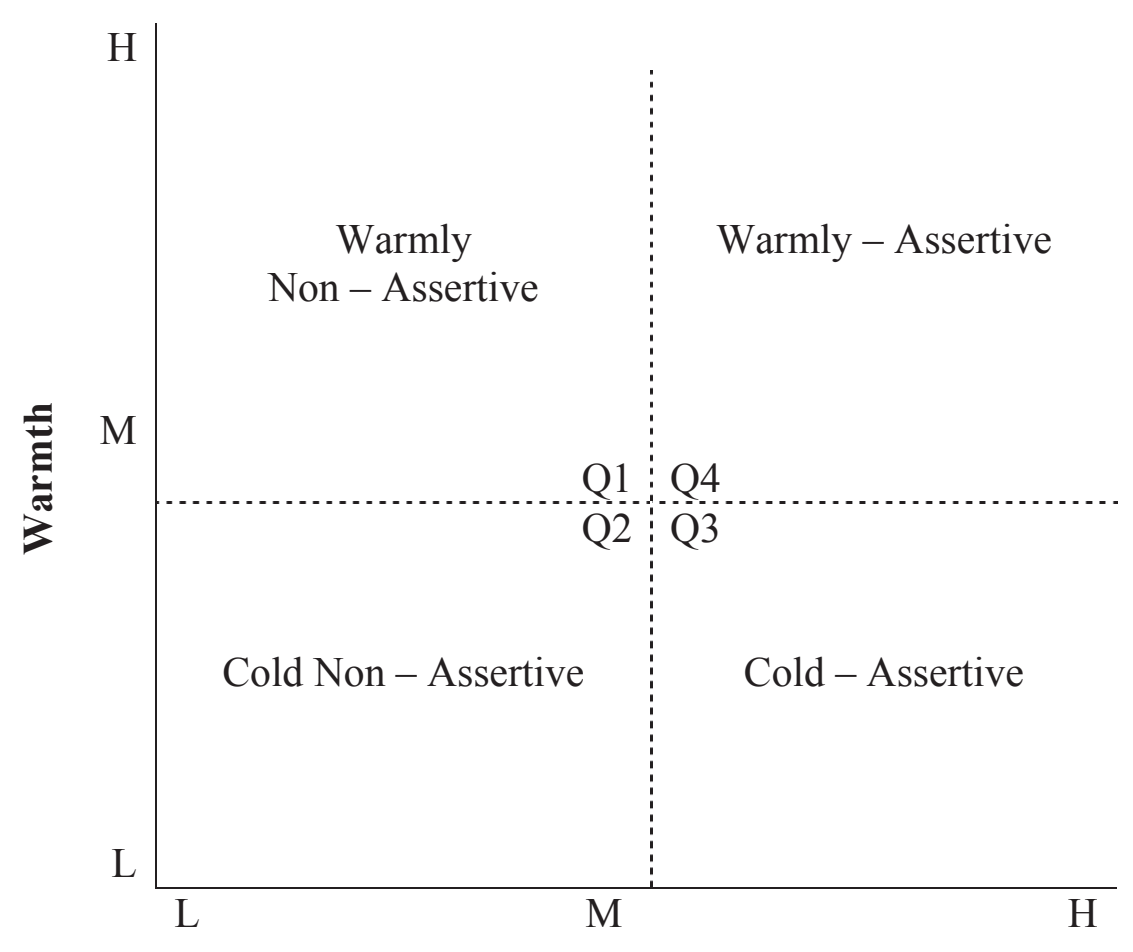

\section{Assertiveness}

This graphic and the related discussion helps the leader visually see how these two dimensions relate to him or her. It also has proven useful to plot the recordings from others who rated the leader. This graphic approach is a useful springboard for discussion around a leader's presence in this behavioral practice area. The Q4 quadrant (Warmly - Assertive) is generally the preferred behavioral space for a leader to be operating in when striving to enhance his leadership presence.

\section{Managing Core Values}

Values are strong convictions that influence attitudes and behaviors at work (Bardi \& Schwartz, 2003). A leader's values, when clearly articulated and lived, strengthen his leadership presence and offer other benefits. For example, there is evidence that "followers" internalize organizational values when they perceive that their leader is acting in alignment with the espoused core values (Biswas \& Suar, 2013; Hannah, Schaubroeck \& Peng, 2016). People prefer to work for leaders who stand for something. A leader who can effectively manage a set of core values by identifying, communicating and living them not only advances his leadership presence but also likely enhances organizational performance and well-being (Kerns, 2018b).

Three open-ended questions are useful to ask the leader and his reports when estimating the extent to which a leader is seen as managing his core values:

1) To what extent does this person have a set of core values? (Please explain).

2) To what extent does the individual clearly communicate his core values? (Please explain).

3) To what extent does this individual live or express his core values on a regular basis at work? (Please explain and provide examples).

This open-ended questioning helps to determine if the leader is managing his core values and to what extent there are shared perceptions between the leader and the other respondents. This process has sometimes led to the leader engaging in a systematic approach to managing core values (Kerns, 2017). 


\section{Ability to Deliver Desired Outcomes/Results}

In the end, a leader needs to produce desired results. A leader showing a high level of leadership presence engages in a process that effectively manages performance to reach desired results. Because there is increasing pressure and accountability for leaders to manage and achieve results, this practice frequently seems to interact with the displaying composure behavioral practice area. In the face of this need to manage results, a leader can enhance his leadership presence by clearly communicating performance expectations, engaging his people, providing effective feedback and ensuring that results are achieved in alignment with a set of core values (Schleichler, Baumann, Sullivan, Levy, Hargrove \& Barros-Rivera, 2018). Leaders with high executive presence also understand that all results are not created equal and that there needs to be criteria on which to judge the value of the results achieved, such as whether the results achieved reflect the organization's core values and were they achieved ethically (Kerns, 2005).

Two questions need to be asked when assessing a leader's presence in relationship to this practice area:

1) Were the desired results achieved?

2) Were they achieved in ways that align with agreed upon criteria?

These two questions need to be assessed and discussed with the leader as well as with the others who were selected to respond with regard to the leader's effectiveness.

\section{Displaying Self-Knowledge and Awareness}

To be effective, a leader needs to be self-aware. This means having a clear understanding of one's strengths and weakness as they relate to the various phases in the process, as well as an accurate view of how he performs each of the leadership presence practices. Every leader needs to be aware of his unique pool of personal resources upon which he draws when executing his functional work role and displaying leadership presence. Key individual difference factors which constitute a leader's unique personal resource pool include such areas as personality, abilities, and strengths. These individual difference making factors influence how a leader performs his performance profile (his functional role) and how he expresses his leadership presence. The facets of a leader's personality, for example, may find him executing his functional role in a more introverted way while other leaders may project more extraversion in getting things done at work. One's unique personality features find expression when projecting his unique leadership presence. Self-knowledge helps bring awareness and insight to different situational contexts to a guide a leader in how to best respond (Carver, 2012).

To obtain information on a leader's level of self-knowledge and awareness, two open-ended questions are asked of the leader, his key reports and other knowledgeable respondents:

1) To what extent does the leader seem to know himself at work? (Please explain and provide examples.)

2) To what extent does the leader demonstrate situational awareness and adapt to situational circumstances effectively? (Please explain and provide examples.)

The eight leadership presence behavioral practices are summarized in Table 1 below. Taken together and as part of personal branding efforts, these leadership presence practices can be used to develop, document and apply a self-image statement. An example of a written self-image statement of leadership presence composed by a leader who was working with the author follows:

"I know myself to be a high-impact communicator who strives to be decisive and warmly assertive while expressing interest and support toward others to hopefully achieve desired $\underline{\text { results }}$ that are aligned with my core values of honesty, fairness and personal responsibility."

Leaders are encouraged to laminate their documented leadership presence self-image statement for easy referencing. It is helpful for leaders to reflect on and savor experiences where they have displayed their self-image, in whole or in part, and to project forward to impending situations where their leadership 
presence will be especially needed. Future projections of leadership presence often surround situations that call for resilience and managing stressful circumstances.

TABLE 1

LEADERSHIP PRESENCE PROFILE

\begin{tabular}{|c|c|c|}
\hline & Behavioral Practice & Definition \\
\hline 1. & High-impact communicating & When an intended message has the desired impact. \\
\hline 2. & Decisive problem-solving & $\begin{array}{l}\text { Reaching desired outcomes by using the right amounts of } \\
\text { quality information within reasonable timeframes. }\end{array}$ \\
\hline 3. & $\begin{array}{l}\text { Showing interest and support in } \\
\text { others }\end{array}$ & $\begin{array}{l}\text { Acting in ways that communicate you care about others } \\
\text { and their development. }\end{array}$ \\
\hline 4. & Displaying composure & $\begin{array}{l}\text { Acting with poise and professionalism even in stressful, } \\
\text { distressing and/or upsetting situations. }\end{array}$ \\
\hline 5. & Showing warm assertiveness & $\begin{array}{l}\text { Communicating needs and intentions clearly with } \\
\text { warmth which encourages others to approach you with } \\
\text { openness. }\end{array}$ \\
\hline 6. & Managing core values & $\begin{array}{l}\text { Documenting, communicating and living a set of core } \\
\text { values. }\end{array}$ \\
\hline 7. & Delivering desired outcomes/results & $\begin{array}{l}\text { Achieving the agreed upon results in alignment with a set } \\
\text { of agreed upon criteria. }\end{array}$ \\
\hline 8. & $\begin{array}{l}\text { Displaying self-knowledge and } \\
\text { awareness }\end{array}$ & $\begin{array}{l}\text { Demonstrating knowledge and awareness of oneself } \\
\text { across differing situational contexts. }\end{array}$ \\
\hline
\end{tabular}

(C) Copyright (2017) Charles D. Kerns, Ph.D., MBA

\section{SOME CHALLENGES}

Evidence gathered from practice, applied research and relevant literature highlights a number of challenges facing organizations and their leaders in the context of leadership presence. Some of these challenges follow.

\section{Gaining Interdisciplinary Perspectives}

Leadership presence as a field of study and practice can be advanced through an interdisciplinary lens. The study of leadership and organizational behavior clearly connect to this topic. Many of the behavioral practices offered here represent important areas of study in these applied behavioral sciences. The field of marketing also seems to be a fertile area for applications that help advance the study and practice of leadership presence (Hodges \& Martin, 2012; Lair, 2005; Ranfagni, Runfola \& Sarti, 2018). In particular, practitioners and applied researchers are challenged to integrate concepts such as personal branding, enhancing brand equity and product differentiation to the practice and review of leadership presence. Leaders as well as those engaged in helping them enhance their leadership presence may benefit from knowing how relevant principles and practices of marketing can be applied to positively impact this work (Heckman, Vestergaard, \& Sole, 2018; Keller, 2012).

Further, the information sciences and the rapidly growing field of neuroscience represent potential opportunities and challenges for leaders to better understand and apply findings from these fields of study to the practice of executive presence. Leaders need to find ways to use technologies to advance their presence, especially when operating in geographically distributed work environments. The recent work with e-branding, for example, may hold promise for leaders wanting to advance their personal brand with the assistance of information technologies and social media (Cooper, 2010; Myers, 2017). There are also numerous ways to apply neuroscience to leadership and leadership presence (Dimitriadis \& Psychogios, 
2016; Fabritius \& Hagemann, 2017). With the increased understanding of how to manage behaviors which influence brain functioning, practitioners will better understand how to manage the behavioral practices associated with leadership presence such as gaining and sustaining composure under stressful conditions (Collins \& Jackson, 2015; Siegel, 2012).

\section{Defining and Measuring}

While leadership or executive presence is frequently referenced, especially in the popular literature, the concept lacks definitional clarity. The current work is intended to help bring additional clarity to this topic by operationally defining it in terms of specific behavioral practices. However, it remains challenging to define and measure. Leadership or executive presence continues to be loosely defined from many perspectives in the literature, including "you will know it when you see it" (Limardi, Morrison \& Morrison, 2014). These nebulous definitions make it challenging to measure and track the developmental progress of leaders who are striving to enhance their presence.

From a practice point of view, it is important that leadership presence be operationally defined so it can be measured - it is challenging to measure a concept without a clear operational definition. The author and his colleagues have developed an operational definition of leadership presence: "displaying of a set of key behavioral practices to achieve desired impacts." In this definition, a set of clear behavioral practices are specified (See also Table 1: Leadership Presence Profile). The successful leader will effectively identify, assess, understand and manage these key behavioral practices. To further advance the practice of enhancing leadership presence, practitioners and applied researchers are challenged to operationalize this concept by specifying sets of specific behavioral practices that can be measured and tracked over time and across varying situational contexts. These efforts will help contribute to identifying, measuring and indexing the impacts of specific leadership presence enhancing practices on organizational outcomes.

\section{Developing Practitioner - Oriented Frameworks}

Additional practice-oriented leadership presence frameworks need to be developed. While there are many conceptual formulations and definitions that address presence, opportunities remain for practitionerminded scholars and practitioners to individually or collectively develop evidence-based models. In these efforts, it would be especially valuable for authors to integrate concepts and knowledge from relevant yet diverse disciplines into their formulations. The practice and study of leadership presence is potentially rich with opportunities to draw upon and integrate key topics from the fields of marketing, leadership, information technologies and organizational behavior. The self-imaging process noted in Phase III (optimizing and integrating), for example, seems to hold promise for interdisciplinary collaboration. This process may benefit from more extensive review from different perspectives such as personal branding, social media/technology assisted messaging and brain functioning.

Given the paucity of evidence-based frameworks for practitioners to review and consider, it would be especially useful for practice-oriented applied researchers to explore approaches that integrate practices into a practical and coherent process. Beyond the framework and approach offered here, applied researchers and/or evidenced based oriented practitioners are challenged to help managerial leaders better understand and manage their leadership presence. For example, the Bates Model of Executive Presence offers a practice-oriented three-dimensional framework which considers character, substance and style (Seitchik, 2019).

\section{Multi-level Alignment and Engagement}

While in practice the enhancement of leadership presence extends across all organizational levels, the focus is often on the individual level. To broaden this perspective, the author suggests a more comprehensive view. Based on work with executives in the field, there are at least three organizational levels with which managerial leaders need to be aligned, engaged, and concerned: individuals, work groups and the overall organization. Tuckey, Bakker and Dollard (2012) highlight the need to investigate frameworks, concepts and practices from a multi-level perspective, indicating that places of work involve 
individuals aligning with groups and teams as well as the larger organization. The managerial leader needs to recognize that her leadership presence exerts an impact on individual employees, work groups and the larger enterprise. She needs to be aware of and manage these impacts as part of her work in enhancing her leadership presence.

In practice, the author and his colleagues frequently ask C-Level executives and their team members to recognize and consider the impacts that their collective executive presence is having on the larger organization. This work helps to put the idea of leadership presence in a broader perspective and reinforces the importance of this practice area. As part of these discussions, the value of having members of an executive team engage with others throughout the organization is emphasized. In connection with executing practices to enhance leadership presence in an engaged way, leaders are also provided with support in their efforts to be engaging (Kerns, 2014). The work of Shuck, Rocco and Alfornoz (2011) underscores the critical role managerial leadership plays in practice areas such as engagement and leadership presence. Practitioners are challenged to adopt a broader view of leadership presence to consider how their presence has a ripple effect and impacts other individuals, groups/teams and the larger organization. They are also challenged to deliver their leadership presence in an engaging way.

\section{Cross Cultural Differences}

Practitioners and applied researchers are further challenged to consider, how leadership presence may be viewed differently across cultures, especially when working with global leaders. House, Dorfman, Javidan, Hanges and Sully de Luque (2014) offer a useful framework for viewing leadership behavior across world cultures. Their work can help global leaders better understand and practice presence with greater sensitivity and effectiveness. For example, in the current leadership presence profile (see Table 1: Leadership Presence Profile); assertiveness is identified as a behavioral practice area. Assertiveness is also a cultural dimension that has been found to vary across cultures by House, et.al (2014). In working with global leaders and their organizations, the author and his colleagues have also found that leadership or executive presence can indeed mean different things depending upon the culture in which it is being viewed.

With the above in mind, leaders and their organizations are challenged to understand and appreciate the potential cross-cultural differences that may exist when viewing and practicing leadership presence. Leaders are particularly urged to practice high-impact communicating when practicing leadership presence in different parts of the world. Understanding and appreciating what may be in others' perceptual filters regarding a specific practice such as assertiveness can help improve communication and one's effectiveness in displaying leadership presence globally.

\section{Exploring the Dark Side}

Leadership presence is largely placed in a positive light when discussed and presented. However, practitioners and applied researchers are challenged to consider the potential darker side of leadership presence. A more balanced perspective may be gleaned by viewing the growing literature on the incidence and causes of managerial leadership ineffectiveness, incompleteness and/or abuse (Bies, Tripp \& Sharpiro, 2016; Jha \& Jha, 2015). This dark side of managerial leadership is being reported at alarmingly high rates with some accounts reporting base rates of managerial incompetence of between fifty percent and seventy-five percent (Kaiser, LeBreton, \& Hogan, 2015). It seems likely that negatively practiced leadership presence may be contributing to these distressing statistics. The recent work relating to the dark side of interorganizational relationships may provide a broader perspective of the negative impacts of the darker sides of leadership presence on organizational functioning (Oliveira \& Lumineau, 2019).

In view of this potential dark side of leadership presence, leaders are challenged to assess and track their effectiveness at executing practices intended to enhance their presence and positively impact others. To accomplish this, an excess rating scale method can be utilized. This method involves the leader specifying a set of behavioral practices such as high-impact communicating and showing interest in others. The leader and selected others are then asked to rate the leader on each of the designated practices 
using a rating scale that can identify excesses and deficiencies for each of the practice areas (Kaiser \& Overfield, 2010). This scale typically asks the respondent to rate a leader in gradients of "too little" to "too much" with the "just right amount" being between the two extremes. By way of example, the author uses the following practice to rate managerial leaders on leadership presence:

Practice: "Shows interest in my development."

Rating Scale:

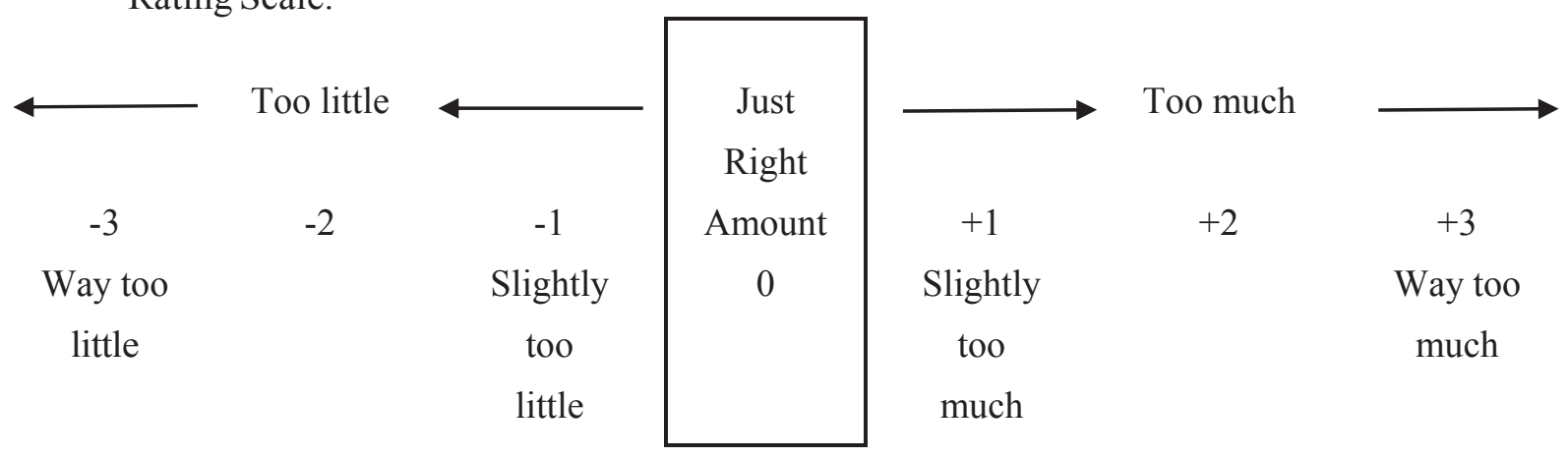

The excess rating scale method can help identify leadership presence practices that are being delivered in "just right amounts", insufficiently and/or excessively. This process will likely help leaders more fully explore the potential dark sides of leadership presence wherein leadership presence practices are executed to excess.

\section{SUMMARY STATEMENT}

Leadership presence can help organizational leaders enhance their competitiveness by positively impacting their personal brand and helping their organizations achieve desired outcomes. Drawing upon relevant literature, applied research, and practice, this framework operationalizes a way for leaders to systematically execute and manage leadership presence. This four-phase process considers key concepts from diverse disciplines. The effective application of the framework to practice requires a set of behavioral practices that can be assessed and developed. There are challenges associated with executing leadership presence in an organizational context, including integrating interdisciplinary perspectives, developing additional practitioner friendly frameworks, and considering multi-level alignments and engagement. Recognizing cross cultural differences and the potential dark sides of leadership presence offer a challenge. When effectively executed, leadership presence will likely help organizations and their leaders attain higher levels of well-being and performance for greater competitiveness.

\section{ENDNOTES}

1. In this article the terms leadership presence, executive presence, and presence are used synonymously. Leaders at all organizational levels as well as aspiring leaders can likely benefit from understanding and applying the concept of presence at work.

2. This system of managerial leadership strives to provide practitioners, applied researchers and teachers with an integrated approach to viewing and understanding leadership. The system brings together several streams of leadership study and research that have been offered over the past 100 years. Concurrently, the development and execution of leadership presence frameworks and associated practices which is the focus of the current article can help advance the practice, study and teaching of leadership. It is, however, beyond the scope of the current presentation to review and discuss the other system dimensions and related practices. 


\section{REFERENCES}

Andrusia, D. \& Haskins, R. (2000). Brand yourself: How to create an identity for a brilliant career. New York, NY: Ballantine Books.

Bardi, A., \& Schwartz, S.H. (2003). Values and behavior: Strength and structure of relations. Personality and Social Psychology Bulletin, 29, 1207-1220.

Baumeister, R.F., Schmeichel, B.J., \& Vohs, K.D. (2007). Self-regulation and the executive function: The self as controlling agent. In A.W. Kruglanski \& E.T. Higgins (Eds.). Social psychology:

Handbook of basic principles (pp. 516-539). New York, NY: Guilford.

Bies, R.J., Tripp, T.M., \& Shapiro, D.L. (2016). Abusive leaders or master motivators? "Abusive" is in the eyes of the beholder. In N. M. Ashkanasy, R.J. Bennett \& M.J. Martinko (Eds.), Understanding the high performance workplace: The line between motivation and abuse (pp. 252-276). New York, NY: Routledge.

Biswas, M., \& Suar, D. (2013). Which employees' values matter most in the creation of employer branding? Journal of Marketing Development \& Competitiveness, 7(1), 93-102.

Bolino, M.C., Kacmar, K.M., Turnley, W.H., \& Gilstrap, J.B. (2008). A multi-level review of impression management motives and behaviors. Journal of Management, 34, 1080-1109.

Buckingham, M., \& Coffman, C. (1999). First break all the rules: What the world's greatest managers do differently. New York, NY: Simon \& Schuster.

Buzzotta, V.R., Lefton, R.E., \& Sherberg, M. (1982). Effective selling through psychology. (Appendix C: Do the dimensional models fit the facts?). Cambridge, MA: Ballinger Publishing Company.

Carver, C. S. (2012). Self-awareness. In M.R. Leary \& J.P. Tangney (Eds.), Handbook of self and identity (2nd ed., pp. 50-68). New York, NY: Guilford Press.

Chierchia, G., \& Singer T. (2016). The neuroscience of compassion and empathy and their link to prosocial motivation and behavior. In J.C. Dreher \& L. Tremblay (Eds.). Decision neuroscience: An integrative perspective (pp. 247-257). Amsterdam: Elsevier.

Clarke, J.S., Cornelissen, J.P., \& Healey, M.P. (2019). Actions speak louder than words: How figurative language and gesturing in entrepreneurial pitches influences investment judgments. Academy of Management Journal, 62(2), 336-360.

Collins, M.D., \& Jackson, C.J. (2015). A process model of self-regulation and leadership: How attentional resource capacity and negative emotions influence constructive and destructive leadership. Leadership Quarterly, 26, 386-401.

Cooper, C.G. (2010). New media marketing: The innovative use of technology in ncaa athletic department e-branding initiatives. Journal of Marketing Development and Competitiveness, 5(1), 23-32.

Crittenden, J.K. (2013). Executive presence. Leadership Excellence, 30, 10.

Cuddy, A.J.C., Tannen, D., \& Su, A.J. (2018). Leadership Presence. Boston, MA: Harvard Business Review Press.

Dagley, G.R., \& Gaskin, C.J. (2014). Understanding executive presence: Perspectives of business professionals. Consulting Psychology Journal: Practice and Research, 66(3), 197-211.

Dimitriadis, N., \& Psychogias, A. (2016). Neuroscience for leaders: A brain-adaptive leadership approach. Philadelphia, PA: Kogan Page.

Duckworth, A., \& Gross, J.J. (2014). Self-control and grit: Related but separable determinants of success. Current Directions in Psychological Science, 23(5), 319-325.

Elsbach, K.D., \& Stigliani, I. (2018). Design thinking and organizational culture: A review and framework for future research. Journal of Management, 44(6), 2274-2306.

Fabritius, F., \& Hagermann, H.W. (2017). The leading brain: Powerful science-based strategies for achieving peak performance. New York, NY: Penguin Random House.

Ferris, D.L., \& Sedikides, C. (2018). Self-enhancement in organizations. In D.L. Ferris, R.E. Johnson, \& C. Sedikides (Eds.). The self at work: Fundamental theory and research (pp. 91-118) New York, NY: Routledge.

106 Journal of Marketing Development and Competitiveness Vol. 13(3) 2019 
Ford, J., Harding, N.H., Gilmore, S., \& Richardson, S. (2017). Becoming the leader: Leadership as material presence. Organizational Studies, 38(11), 1553-1571.

Goffman, E. (1959). The presentation of self in everyday life. New York, NY: Doubleday.

Hannah, S.T., Schaubroeck, J.M., \& Peng, A.C. (2016). Transforming followers' value internalization and role self-efficacy: Dual processes promoting performance and peer norm-enforcement. Journal of Applied Psychology, 101(2), 252-266.

Harms, P.D., Credé, M., Tynan, M., Leon, M., \& Jeung, W. (2017). Leadership and stress: A metaanalytic review. Leadership Quarterly, 28, 178-194.

Heckman, P.E., Vestergaard, A.J., \& Sole, K.M. (2018). Guiding principles model: A call to integrate the 4 p's into a strategic construct. Journal of Marketing Development \& Competitiveness, 12(4), 6068.

Hewlett, S.A., Leader-Chivee, L., Sherbin, L., Gordon, J., \& Dieudonnè, F. (2012). Executive presence. New York, NY: Center for Talent Innovation.

Hodges, J., \& Martin, G. (2012). Can leadership branding work in theory and practice to resolve the integration-responsiveness problems facing multinational enterprises? The International Journal of Human Resource Management, 23(18), 3794-3812.

House, R.J., Dorfman, P.W., Javidan, M., Hanges, P.J., \& Sully de Luque, M.F. (2014). Strategic leadership across cultures: The globe study of ceo leadership behavior and effectiveness in 24 countries. Thousand Oaks, CA: Sage.

Jha, S., \& Jha, S. (2015). Leader as anti-hero: Decoding nuances of dysfunctional leadership. Journal of Management \& Public Policy, 6(2), 21-28.

Johns, G. (2006). The essential impact of context on organizational justice. Academy of Management Review, 31(2), 386-408.

Kaiser, R.B., \& Overfield, D.V. (2010). Assessing flexible leadership as a mastery of opposites. Consulting Psychology Journal: Practice and Research, 62, 105-118.

Kaiser, R.B., LeBreton, J.M., \& Hogan, J. (2015). The dark side of personality and extreme leader behavior. Applied Psychology, 64(1), 55-92.

Keller, K.L. (2010). The new branding imperatives: Insights for the new marketing realities. Boston: Marketing Science Institute.

Keller, K.L. (2012). Strategic brand management: Building, measuring, and managing brand equity, 4th Edition. New York, NY: Pearson.

Kerns, C.D. (2001). The power of performance profiling: Eight good reasons to concentrate on results. Graziadio Business Review, 4(1).

Kerns, C.D. (2005). Are all results created equal? Auditing organizational outcomes for quality. Total Quality Management \& Business Excellence, 16(7), 827-840.

Kerns, C.D. (2013). Self-control at work: Managing "hot buttons". Graziadio Business Review, 16(3).

Kerns, C.D. (2014). Fostering and managing engagement: A framework for managerial leaders. Journal of Leadership, Accountability and Ethics, 11(1), 34-49.

Kerns, C.D. (2016a). High-impact communicating: A key leadership practice. Journal of Applied Business and Economics, 18(5), 11-24.

Kerns, C.D. (2016b). Decisive problem solving: A key leadership practice. Journal of Management Policy and Practice, 17(2), 66-77.

Kerns, C.D. (2016c). Leadership presence practice index. Unpublished instrument.

Kerns, C.D. (2017). Managing leader core values at work: A practice-oriented approach. Journal of Leadership, Accountability and Ethics, 14(1), 11-21.

Kerns, C.D. (2018a). Leader life-span experience management. A practice-oriented approach. Journal of Applied Business and Economics, 20(8), 105-119.

Kerns, C.D. (2018b). Impacting well-being at work: A key managerial leader action role. Journal of Management Policy and Practice, 19(1), 73-91.

Kerns, C.D. (2019). Leadership/executive factors and practices checklist. Unpublished instrument. 
Kowalski, R.M., \& Leary, M.R. (1990). Strategic self-presentation and the avoidance of aversive events: Antecedents and consequences of self-enhancement and self-depreciation. Journal of Experimental Social Psychology, 26, 322-336.

Kyratsis, Y., Atun, R., Phillips, N., Tracey, P., \& George, G. (2017). Health systems in transition: Professional identity work in the context of shifting institutional logics. Academy of Management Journal, 60(2), 610-641.

Ladkin, D. \& Taylor, S.S. (2010). Enacting the 'true self': Towards a theory of embodied authentic leadership. The Leadership Quarterly, 21, 64-74.

Lair, D.J. (2005). Marketization and the recasting of the professional self: The rhetoric and ethics of personal branding. Management Communication Quarterly, 18(3), 307-343.

Leary, M.R. \& Bolino, M.C. (2018). An actor-perceiver model of impression management in organizations. In D. L. Ferris, R.E. Johnson, \& C. Sedikides (Eds.), The self at work:

Fundamental theory and research (pp. 253-272) New York, NY: Routledge.

Leroy, H., Anseel, F., Gardner, W.L. \& Sels, L. (2015). Authentic leadership, authentic followership, basic need satisfaction, and work role performance: A cross-level study. Journal of Management, 41(6), 1677-1697.

Limardi, D., Morrison, D., \& Morrison, D. (2014). Executive presence: Do you have the leadership "wow" factor? Public Management, June 2014, 6-10.

Lord, R.G., \& Chui, S.L.M. (2018). Dual process models of self-schemas and identity: Implications for leadership and fellowship processes. In D.L. Ferris, R.E. Johnson, \& C. Sedikides (Eds.), The self at work: Fundamental theory and research (pp. 341-361). New York, NY: Routledge.

Love, E.G., Lim, J., \& Bednar, M.K. (2017). The face of the firm: The influence of ceo's on corporate reputation. Academy of Management Journal, 60(4), 1462-1481.

Macaux, W. \& Bates, S. (2015), How will cios use their growing influence? CIO Insight, 3/5/2015.

Marques, J.F. (2006). The spiritual worker: An examination of the ripple effect that enhances quality of life in and outside the work environment. Journal of Management Development, 25(9), 884-895.

Mawritz, M.B., Greenbaum, R.L., Butts, M.M., \& Graham, K.A. (2017). I just can't control myself: A self-regulation perspective on the abuse of deviant employees. Academy of Management Journal, 60(4), 1482-1503,

Mitchell, M.S., Greenbaum, R.L., Vogel, R.M., Mawritz, M.B. \& Keating, D.J. (2019). Can you handle the pressure? The effect of performance pressure on stress appraisals, self-regulation and behavior. Academy of Management Journal, 62(2), 531-552

Murphy, N.A. (2007). Appearing smart: The impression management of intelligence, person perception accuracy, and behavior in social interaction. Personality and Social Psychology Bulletin, 33, $325-$ 339.

Myers, J. (2017). Brand yourself on youtube: The design, execution, and reflection of a three-fold experiential exercise. Journal of Marketing Development and Competitiveness, 11(1), 11-18.

Oliveira, N., \& Lumineau, F. (2019). The dark side of interorganizational relationships: An integrative review and research agenda. Journal of Management, 45(1), 231-261.

Pfeffer, J., \& Fong, C.T. (2005). Building organizational theory from first principles: The selfenhancement motive and understanding power and influence. Organization Science, 16, 372-388.

Ranfagni, S., Runfola, A. \& Sarti, D. (2018). International expansion based on a locally authentic brand: Issues and findings from italian case studies. Journal of Marketing Development and Competitiveness, 12(1), 124-136.

Schleicher, D.J., Baumann, H.M., Sullivan, D.W., Levy, P.E., Hargrove, D.C. \& Barros-Rivera, B.A. (2018). Putting the system into performance management systems: A review and agenda for performance management research. Journal of Management, 44(6), 2209-2245.

Seitchik, M. (2019). The goldilocks approach to team conflict: How leaders can maximize innovation and revenue growth. The Psychologist-Manager Journal, 22(1), 37-45.

Shuck, B., Rocco, T.S., \& Albornoz, C.A. (2011). Exploring employee engagement from the employee perspective: Implications for HRD. Journal of European Industrial Training, 35, 300-325.

108 Journal of Marketing Development and Competitiveness Vol. 13(3) 2019 
Siegel, D.J. (2012). Pocket guide to interpersonal neurobiology. New York, NY: Norton.

Spear, S., \& Roper, S. (2013). Using corporate stories to build the corporate brand: An impression management perspective. Journal of Product \& Brand Management, 22(7), 491-501.

Trump, R. \& Brucks, M. (2010). Overlap and dissociation of mental representations of self and brand. Advances in Consumer Research, 37, 473-474.

Tuckey, M.R., Bakker, A.B., \& Dollard. M.F. (2012). Empowering leaders to optimize working conditions for engagement: A multilevel study. Journal of Occupational Health Psychology, 17(1), 15-27.

van den Bosch, R., Taris, T.W., Schaufeli, W.B., Peeters, M.C.W. \& Reijseger, G. (2019). Authenticity at work: A matter of fit? Journal of Psychology, 153(2), 247-266.

van Knippenberg, D. (2016). Making sense of who we are: Leadership and organizational identity. In M.G. Pratt, M. Schultz, B.E. Ashforth \& D. Ravasi (Eds.), The oxford handbook of organizational identity (pp. 335-349). New York, NY: Oxford University Press.

Vandaveer, V.V., Lowman, R.L., Pearlman, K., \& Brannick, J.P. (2016). A practice analysis of coaching psychology: Toward a foundational competency model. Consulting Psychology Journal: Practice and Research, 68(2), 118-142.

Voros, S. (2000). The road to ceo: The world's leading executive recruiters identify the traits you need to make it to the top. Avon, MA: Adams Media.

Wagner, R., \& Harter, J.K. (2006). The 12 elements of great managing. New York, NY: Gallup Press.

Zaccaro, S.J., Green, J.P., Dubrow, S., \& Kolze, M. (2018). Leader individual differences, situational parameters, and leadership outcomes: A comprehensive review and integration. Leadership Quarterly, 29, 2-43. 